\title{
PRÉSTAMOS Y CULTURA LINGÜÍSTICA EN LA COMUNICACIÓN DE CIENCIA EN ESPAÑOL
}

\author{
Guiomar Elena Ciapuscio*
}

\begin{abstract}
Resumo: $O$ objetivo deste trabalho é estudar a variedade científica do espanhol, definida por parâmetros diafásicos (divulgação científica especializada) e diatópicos (o espanhol escrito na Argentina) representado paradigmaticamente na revista Ciencia Hoy. Neste artigo, são examinadas as atitudes lingüísticas em relação aos empréstimos encontrados nesta revista, em sua maioria termos, a partir da análise de uma amostra dos seus últimos volumes. Por um lado, proponho-me a determinar se as intenções explícitas na normativa de evitar os anglicismos se realizam nos usos e onde se encontra a força de maior penetração do inglês; por outro lado, pretendo examinar os modos de introdução dos empréstimos e de que maneira se "trabalha" linguisticamente sobre eles, mediante procedimentos de reformulação e qualificação metadiscursiva. Com base na análise qualitativa de vários exemplos, discute-se o grau de integração dos empréstimos nos textos.
\end{abstract}

Palavras-chave: Variedades do espanhol, anglicismos, comunicação da ciência, terminologia.

\section{INTRODUCCIÓN}

En primer lugar deseo agradecer la invitación de los editores de este número especial de Órganon por convocarme a colaborar en la celebración de los 20 años de Termisul. Quiero recordar aquí que conocí a María da Graça Krieger, su directora por muchos años, cuando ambas nos desempeñábamos como coordinadoras de las Comisiones de Terminología del Mercosur (en el marco de la Reunión Especializada en Ciencia y Tecnología, RECYT); nos unían la misma formación, el interés disciplinar y la preocupación por colaborar con el enriquecimiento del portugués y del español americanos, en las áreas de las ciencias y las tecnologías. La experiencia de aquella comisión, en la que practicábamos un convencido y efectivo bilingüismo, fue muy fértil y trascendió ampliamente los deberes institucionales que allí teníamos: los grupos de investigación Termisul y Termtex ${ }^{1}$ desarrollaron proyectos de investigación conjuntos, que dieron como resultado publicaciones científicas en el área de la terminología y los textos especializados, realizaron seminarios y cursos de posgrado en la UFRGS y en la UBA y siguen cultivando al día de hoy vínculos académicos sólidos y fructíferos, que se continúan en los investigadores más jóvenes.

En esta contribución presentaré resultados parciales de mi trabajo de investigación, dirigido a estudiar los textos que producen los científicos argentinos cuando comunican sus investigaciones a un público que denominaré provisoriamente culto ${ }^{2}$. Mi propósito es describir y profundizar en el conocimiento de esta variedad, definida por parámetros diafásicos (el discurso científico - la divulgación alta de ciencia) y diatópicos (el español escrito en Argentina), y

\footnotetext{
* Guiomar Elena Ciapuscio, Universidad de Buenos Aires, Consejo Nacional de Investigaciones Científicas y Técnicas.

${ }^{1}$ Grupo Argentino de investigación y docencia en Terminología y Texto (www.caicyt.gov.ar).

${ }^{2}$ El trabajo se enmarca en el proyecto en curso "Variedades generales y especializadas del Español de la Argentina" (PICT 15512007), financiado por la Agencia Nacional de Promoción Científica y Tecnológica.
} 
representada paradigmáticamente en la revista Ciencia $\mathrm{Hoy}^{3}$. En ella, académicos de todas las disciplinas dan a conocer sus trabajos de investigación de una manera rigurosa pero comprensible para un público relativamente amplio (pares de otras disciplinas, ciudadanos interesados en la ciencia, profesores del nivel medio). Ciencia Hoy nació en 1988 como contraparte hispanohablante de la consagrada revista brasileña, Ciência Hoje, que fue tomada de manera explícita como "modelo" de la revista argentina, sobre la base de relaciones académicas entre especialistas de ambos países. La colaboración entre ambas publicaciones se mantiene, hecho que se refleja en la publicación de artículos de las contrapartes e, incluso, de ediciones conjuntas de números especiales ${ }^{4}$.

Un tema central de mis investigaciones sobre estos textos especializados es la reconstrucción de los modelos y orientaciones normativas explícitas e implícitas que delinean el perfil y determinan las características lingüístico-textuales de esta variedad lingüística. Siguiendo a Lara (1976), que retoma la tradición de la lingüística praguense (HAVRÁNEK, 1936), considero que la norma es un concepto complejo de orden metalingüístico, establecido por la fuerza social de una comunidad de usuarios de la lengua, que orienta en ella su actividad discursiva: los hablantes tienen la capacidad de normar sus expresiones de acuerdo con unos determinados modelos de aceptabilidad dependientes de factores de orden diatópico, diastrático y diafásico. Las normas lingüísticas son, entonces, representaciones de los hablantes de orden modélico, que tienen un carácter más o menos consciente, más o menos codificado ${ }^{5}$. Esas normas se cristalizan bajo la forma de tradiciones escritas y habladas, y constituyen "la competencia histórica y real" (LARA 2007, p.179) de las comunidades lingüísticas. Las representaciones normativas de un grupo dado de hablantes pueden reconstruirse y analizarse a partir de su propia actividad metalingüística: distintos autores han destacado la importancia de la actividad metalingüística de los hablantes en la expresión, ponderación y fijación de la normas. Como lo ha demostrado Antos (1982, p. 73-74), los hablantes, al comentar y evaluar expresiones, sean simples o complejas, se orientan en normas de referencia a las que subyacen dimensiones de valoración: este autor sistematiza esas dimensiones a partir de una adaptación de las máximas de Grice, que enriquece con máximas adicionales. A continuación, las dimensiones de valoración que propone Antos:

- Dimensión de la constitución secuencial (que corresponden a la máxima "Be orderly");

- Dimensión de relevancia ("Be relevant" y "Be brief”);

- Dimensión de la adecuación al objeto ("Be true");

- Dimensión de comprensibilidad ("Avoid obscurity of expression", “Avoid ambiguity");

- Dimensión de relación (interaccional);

- Dimensión de la imagen (tanto del hablante como del interlocutor);

- Dimensión estética (del texto o elemento lingüístico evaluado).

Este repertorio de dimensiones ordena las valoraciones normativas que los hablantes realizan cuando hablan o escriben; nos permiten comprender cuál es el plano de la comunicación evaluado.

\section{LA ACTIVIDAD MATALINGÜISTICA EN LOS TEXTOS CIENTÍFICOS}

\footnotetext{
${ }^{3}$ http://www.cienciahoy.org.ar/vol1.htm.

${ }^{4}$ Es el caso, por ejemplo, del número especial por el 20 aniversario de Ciencia Hoy (volumen 18, número 108), que incluye un suplemento bilingüe, redactado por científicos de Brasil y Argentina.

${ }_{5}^{5}$ Así, las normas de las Academias constituirían "el grado más elevado de codificación y conciencia, mientras que las demás se registrarían en un menor grado de conciencia y en un menor grado de codificación". Los hablantes se ajustan a un modelo aceptable para su comunidad, para la situación comunicativa, pero tal obligación tiene un carácter "natural", que surge de la realidad del lenguaje en su uso social (Lara 1976: 93).
} 
En el campo de la comunicación científica o especializada la preocupación por la forma lingüística está establecida en las diferentes disciplinas, y las zonas prescriptivas de las publicaciones especializadas exhiben con claridad el cuidado por el estilo, las normas y las convenciones. En trabajos previos (cfr. Ciapuscio, en prensa) he puesto de manifiesto cómo los científicos argentinos y mexicanos, cuando comunican sus trabajos al público culto, demuestran una genuina preocupación por el lenguaje y por sus textos; su quehacer en este plano representa una forma particular de lo que podría llamarse siguiendo a Antos (1996) una lingüística de legos: la importancia del trabajo, la reflexión y la crítica metalingüística en sus textos muestra la mirada atenta y reflexiva de los miembros de esta comunidad de discurso que posee y cultiva una cultura escrita especial, una de cuyas máximas comunicativas centrales es la precisión, y que compete tanto a los aspectos conceptuales como formales. Una muestra del trabajo metalingüístico y de esta actitud de los científicos se encuentra en el siguiente intercambio de cartas de lectores de Ciencia Hoy, en la cual el lector objeta el incumplimiento de las convenciones disciplinares y el empleo de determinada terminología; en su respuesta, los editores admiten algunos errores tipográficos y de convención, pero también discuten y rechazan otros:

\section{Cuestiones de nomenclatura}

En primer lugar, una felicitación por el editorial del número 84 "Una mutación del Homo academicus". El personaje que describe es abundante y, lamentablemente, resulta promovido por los medios y hasta premiado por sociedades extrajeras. La descripción que hace el editorialista ayudará a desenmascarar estos especímenes. Dicho esto, permítanme notar, a propósito de los buenos artículos sobre nanotecnología publicados en el mismo número que no siempre se respetaron las convenciones internacionales en cuanto a símbolos y terminología. Así, se usó micrón en vez de micrómetro y, como símbolo de esa unidad, Mn (que significa megametro) en lugar de $\mu \mathrm{m}$. En otro lugar se simbolizó la energía de Fermi con $\mu$, escrito en tipografía redonda, cuando debió ponerse en cursiva por ser una magnitud: además el símbolo acordado es Er. Se mezclaron magnitudes con unidades al escribir que la corriente I (debió ser I) no es proporcional al voltaje $V$ (debió decir al potencial eléctrico, símbolo $V$, ya que $V$ en tipo redondo es el símbolo de volt). En otra nota se usó Torr (símbolo del torricelli) como unidad de presión, caída en desuso hace más de 30 años, en lugar del pascal (símbolo Pa). Sugiero que el respeto por la simbología internacional sea una política editorial, como se viene recomendando desde hace ya bastante tiempo.

Luis F. Bertello - Chemiconsult, San Isidro

\section{Respuesta}

Se agradece al lector su comentario sobre el editorial (en cuyo título, Homo academicus debió haber aparecido en itálica, como estaba en el original que fue a composición, pero...). Sus observaciones sobre nomenclatura y simbología son muy oportunas y apuntan en la dirección en la que CIENCIA HOY procura avanzar para hacer un uso aceptado e inequívoco de la terminología sobre magnitudes y unidades. Hay, sin embargo, que tener en cuenta que los usos y costumbres muchas veces no se amoldan (o tardan en amoldarse) a las convenciones internacionales, aun entre científicos y tecnólogos. En ese sentido, el empleo del término micrón, como simplificación del vocablo micrómetro (no como unidad que lo sustituye), puede entrar en la categoría de lo aceptado, no así su sinónimo micra, el cual se fue eclipsando pero, como aquél, figura en el diccionario de la Real Academia Española, que define a ambos como la millonésima parte de un metro. Éste, como se sabe, es la unidad de longitud, una de las siete fundamentales (las otras son el kilogramo, el segundo, el amperio, la candela, el mol y el kelvin) del sistema internacional de medidas (cuya sigla es SI en cualquier idioma), aprobado en 1960 por la XI conferencia internacional de pesas y medidas y, consecuentemente, base del sistema métrico legal argentino. Mm fue, como la del título del editorial, otra errata (la letra griega $\mu$ salió como M, algo que no se advirtió en la corrección). También la $\mu$ de la energía de Fermi debió aparecer en itálica y, si bien es más frecuente indicarla con la notación EF, la $\mu$ es preferida por muchos autores. Lo mismo sucedió con la corriente eléctrica, que debió expresarse como I (cursiva), y con la 
diferencia de potencial, que debió ir como $V$ (cursiva). El término voltaje es un anglicismo aceptado (voltage) para expresar la diferencia de potencial. El Pascal es, por cierto, la unidad del sistema internacional para medir presión. Pero el uso de milibares (milésimas de bar) es común en Europa, y el de Torr en los EEUU y Asia. La presión de vacío se expresa generalmente en Torr, unidad que no parece haber caído tan en desuso. Los editores coinciden con la recomendación del lector Bertello de incorporar a las políticas editoriales el respeto por la nomenclatura y la simbología internacionales. Erratas aparte, así lo han tratado de hacer. Al mismo tiempo, han querido en muchos casos respetar las unidades utilizadas por los autores, en especial en aquellos casos en que reflejan los usos y costumbres de alguna rama disciplinaria o profesión. En los medios técnicos locales del automóvil, para poner un ejemplo elocuente, resultaría incomprensible especificar que en verano se inflen las gomas hasta $200 \mathrm{kPa}$, en vez de hasta las consabidas 29 libras (o, más técnicamente, PSI, del inglés pounds per square inch, libras por pulgada cuadrada). En Europa hablarán de $\mathrm{kg}$ por cm cuadrado. En lo sucesivo, CIENCIA HOY procurará señalar esos desvíos de los usos y costumbres con relación a las convenciones internacionales y, cuando sea del caso, dar ambas unidades.

La transgresión a la máxima "Be clear", "Avoid ambiguity", que afecta la dimensión de comprensibilidad, está puesta en foco en este intercambio, en el que puede observarse una profusa actividad metalingüística; sin embargo, el cuestionamiento de las formas que realiza el lector afecta también las dimensiones que conciernen a la imagen ("face") de los interlocutores: de manera cortés, realiza actos de habla que amenazan la imagen de los editores, al cuestionar el uso inadecuado de la simbología, los errores de formato que afectan las convenciones disciplinares, el empleo de determinadas unidades de medida, y más subrepticiamente, el uso de un supuesto anglicismo (destacado con subrayado), todo lo cual colabora en la constitución de su perfil de "experto". Los editores, apelando a autoridades normativas diversas, admiten, corrigen, relativizan y, en el caso del anglicismo, refutan: El término voltaje es un anglicismo aceptado (voltage) para expresar la diferencia de potencial.

La actitud reticente hacia los llamados extranjerismos o préstamos es una constante en las normas de escritura que generalmente incluyen las revistas de alta divulgación científica en español ${ }^{6}$. Sin embargo, cuando se analizan los artículos de los especialistas, surge que esa norma se transgrede con cierta regularidad: la presencia de unidades léxicas del inglés, especialmente, en ciertos campos del saber es frecuente. Esa tensión entre norma explícita y usos que la colisionan merece un examen detenido.

\section{Préstamos}

La introducción de palabras extranjeras en una lengua - que reciben el nombre de préstamoses un hecho lingüístico-cultural que se produce entre idiomas en contacto. Los préstamos son, como sabemos, una importante y legítima fuente de neologismos, junto a los procedimientos basados en los propios recursos, como la derivación y la composición. Este fenómeno puede implicar distintas actitudes que van desde la incorporación masiva de términos, sin adaptación a los esquemas de la lengua receptora, hasta el rechazo sistemático y purista de los extranjerismos (DÍAZ ROJO, 1995, p. 44). Como es sabido, la necesidad de crear unidades léxicas especializadas es expansiva en ciencia (WEINRICH, 1995) y una de las fuentes principales de la neología en este ámbito son justamente los préstamos, que pueden o no estar adaptados. Sin embargo, existe una tradición establecida en el discurso de las ciencias sobre la lengua científica de orientación claramente prescriptiva: una posición purista que proscribe - entre otras cosas los préstamos y sostiene que "no debemos usar extranjerismos nunca". Como es típico de las orientaciones prescriptivas se acuñan metáforas elocuentes del rechazo a las formas prohibidas,

\footnotetext{
${ }^{6}$ También encontramos esta norma restrictiva en la revista mexicana Ciencia y Desarrollo (www.conacyt.mx/comunicacion/revista/215/Artículos/Para).
} 
vinculándolas con campos conceptuales negativos como el de las plagas, la suciedad, la fealdad y la pereza. A continuación, algunos ejemplos:

- "Los extranjerismos son la "carcoma" de la lengua"7.

- "En los cinco primeros capítulos de la monografía me ocupo de los falsos amigos y las palabras de traducción engañosa, causa frecuente de extranjerismos, que no solo restan belleza al idioma y proclaman la pereza del autor, sino que en ocasiones modifican sustancialmente el sentido de un texto". ${ }^{8}$

- "Los extranjerismos siguen entrando violentamente en nuestro idioma y permanecen en él, desplazando en ocasiones a los términos autóctonos, en lo que muy bien podríamos llamar "parasitismo lingüístico. Las palabras traidoras continúan salpicando de sinsentidos las traducciones médicas y las publicaciones en castellano basadas en bibliografía extranjera (que son casi todas)". "

Reiteradamente se ha afirmado que el empleo de préstamos se explica a partir de causas lingüísticas y extralingüísticas (PRATT, 1980; CABRÉ, 1993; DIÉGUEZ, 2005). El inglés, como es sabido, es la lengua franca internacional, por razones políticas y económicas; su papel en la comunicación científica y académica es absolutamente dominante desde entrado el siglo $\mathrm{XX}$ : algunas disciplinas como las matemáticas son monolingües en inglés y en muchas otras como las ciencias naturales - no se discute su hegemonía (KRETZENBACHER, 2001, p.452); un panorama algo diferente se encuentra en las ciencias sociales y las humanidades de lenguas distintas del inglés, que suelen esgrimir una actitud más crítica y que tienden, por el tipo de objeto de investigación, al uso de las lenguas vernáculas y a una apertura mayor a consultar literatura en distintas lenguas. Las actitudes ante la lengua hegemónica, naturalmente, varían también según las tradiciones culturales, las políticas lingüísticas y la situación geográficopolítica de la comunidad dada. En el caso de la actividad científica en las ciencias exactas y naturales, pero también en otras, como la economía, la informática o la administración y negocios en que los países angloparlantes forman parte protagónica del liderazgo mundial, las causas del empleo dominante del inglés son también de orden lingüístico: la necesidad denominativa que surge en el quehacer investigativo lleva a que los conceptos nuevos (sean objetos, procesos, técnicas o tecnologías) reciban su primer nombre en inglés, que sean usados en un primer momento solo en esa lengua y que solo un tiempo después - y no siempre - se cree el neologismo o la alternativa en español (u otra lengua). En este sentido, las revistas de alta divulgación de ciencia, como Ciencia y Desarrollo y Ciencia Hoy, cumplen un papel sumamente importante en el proceso de enriquecer el español científico, al establecer, sobre la base de los recursos del sistema, las nuevas denominaciones o equivalencias, esto es, al crear neologismos, o al difundir las formas existentes de escaso conocimiento en la comunidad lingüística.

\section{OBJETIVOS DEL TRABAJO Y METODOLOGÍA}

Ciencia Hoy es una publicación que exhibe no solo una alta calidad técnica, sino también una importante preocupación por el cuidado de la lengua y del estilo. La sección "Recomendaciones para autores" contiene información sobre las metas político-sociales que persigue Ciencia Hoy, metas que, en mi opinión, impactan sensiblemente en la configuración de la actitud normativa de los editores. Ciencia Hoy explicita que aspira a "lograr que la actividad científica obtenga reconocimiento social e intervenga en la modernización del país”; en su editorial fundacional del año 1988, además, afirma:

\footnotetext{
${ }^{7}$ Juan José Alzugaray (2004).

${ }^{8}$ Fernando Navarro y Francisco Hernández (1997:9).

${ }^{9}$ Ibidem, p.21.
} 
CiEnCia Hoy se publicará en castellano, lo cual le permitirá el acceso al resto de los países de Latinoamérica. En la mayoría de ellos la ciencia se enfrenta con problemas similares a los de la Argentina. Los editores confían en que la revista llegue a ser un agente eficaz para favorecer la integración y la cooperación científica en la región.

Este propósito "integracionista" se refleja en las orientaciones normativas de la revista, que persigue lograr un castellano "culto", orientado en los preceptos de autoridades lingüísticas reconocidas (cfr. CIAPUSCIO, en prensa) ${ }^{10}$; en una de las normas para el envío de los manuscritos, Ciencia Hoy limita severamente el uso de unidades léxicas extranjeras, mediante la siguiente indicación: "Usar el lenguaje más sencillo posible. No emplear palabras extranjeras si hubiese razonables equivalentes castellanos. Evitar neologismos, muletillas y expresiones de moda."

En este trabajo mi propósito general es profundizar en las actitudes lingüísticas frente a los préstamos de Ciencia Hoy, a partir del examen de una muestra ejemplar de los últimos volúmenes de la revista. Me propongo determinar en qué medida las intenciones explícitas en la normativa se realizan en los usos; por otra parte, deseo examinar los modos de introducción de los préstamos, y de qué manera se "trabaja" lingüísticamente sobre ellos. Más precisamente, las preguntas que pretendo responder son:

- ¿Cuándo se incluyen unidades léxicas del inglés en una revista que procura evitarlos?

- Los préstamos ise incorporan por necesidad, por ausencia de equivalencias en español? ¿O su presencia se debe atribuir a otras razones, de orden textual y/o pragmático (cfr. DIÉGUEZ, 2005)?

- ¿Existe una distribución de los préstamos sesgada según la disciplina? En otros términos, es la variable "disciplina" un condicionante de la ocurrencia de préstamos del inglés?

- ¿De qué modo se introducen los préstamos del inglés? ¿En qué medida y con qué recursos los escritores señalan la diferencia de código? ¿Qué información aportan los distintos marcadores metalingüísticos y qué relevancia tienen para la comprensión de los usos?

- Finalmente, ¿con qué dimensiones normativas (cfr. ANTOS, supra) puede vincularse y explicarse el uso de unidades del inglés?

A partir de una muestra ejemplar de la revista Ciencia Hoy me propongo responder de manera preliminar a estas preguntas y de este modo aportar al conocimiento acerca de dónde está la presencia y la fuerza de penetración mayor del inglés en el discurso científico que se quiere escribir en español. La muestra, que considera géneros de opinión (editoriales y cartas de lectores) e informativos (artículos y, parcialmente, los glosarios que suelen acompañarlos), se compone de los volúmenes 18, 19 y 20 correspondientes a los años 2008, 2009 y 2010; en total 17 números de la revista ${ }^{11}$. No se tomaron en cuenta artículos traducidos de otras lenguas y tampoco las expresiones en inglés presentes en citas de títulos originales.

El procedimiento seguido es el siguiente: en primer lugar se han identificado y extraído las secuencias textuales que incluyen unidades léxicas del inglés. En segundo lugar, se ha llevado a cabo un análisis estructural y funcional de los segmentos, que incluyó las siguientes variables:

- Distribución disciplinar de los préstamos;

- Presencia/ausencia de equivalencias en español;

- Presencia/ausencia de actividades de tratamiento reformulativo;

- Orden de ocurrencia, es decir, si el préstamo antecede o sigue a la equivalencia o expresión clarificadora en español;

\footnotetext{
${ }^{10}$ En un apartado de las Recomendaciones para autores, bajo el título de "Política Editorial" puede leerse: "Toda nota aceptada para su publicación, luego de concluido el proceso de arbitraje, pasa por un minucioso procesamiento de estilo: en la práctica, casi todas las contribuciones son redactadas nuevamente por el equipo editorial de la revista, para adaptarlas a las necesidades de los lectores. En todos los casos se solicita al autor que apruebe el texto reformado. El uso del idioma en la revista se ajusta a las normas y los criterios de castellano culto y, en especial, a lo establecido por la Real Academia Española, por lo que a veces no coincide con las prácticas de ciertas revistas científicas o tecnológicas."

${ }^{11}$ Puede accederse a los índices y a los textos de las revistas en la página http://www.cienciahoy.org.ar/indice.htm.
} 
- Ocurrencia y modo de realización de las siglas;

- Presencia/ausencia de actividades de calificación metadiscursiva (GÜLICH y KOTSCHI, 1995; CIAPUSCIO, 2007), tipos de marcadores metalingüísticos del préstamo;

- Funciones textuales y pragmáticas de los préstamos.

A lo largo del artículo se analizan cualitativamente variados ejemplos del corpus y, sobre esa base, se intenta responder los interrogantes planteados. Finalmente, recapitulo los resultados y presento unas reflexiones finales.

\section{ANÁLISIS Y RESULTADOS}

\section{Datos: equivalencias y distribución}

El relevamiento realizado dio como resultado la presencia en el corpus de 82 unidades lingüísticas del inglés de distinto grado de complejidad (palabras, sintagmas, oraciones), aunque predominan los sintagmas nominales. La mayoría de ellos se encuentran en los artículos escritos por especialistas; sin embargo, esporádicamente, se emplean en los editoriales (8 ejemplos), que redactan los editores responsables y, en menor medida, en las cartas de lectores (2). En la siguiente tabla, se presenta la distribución por disciplina de las unidades del inglés ${ }^{12}$ :

\begin{tabular}{|l|l|l|l|}
\hline Disciplina & $\begin{array}{l}\text { Número de } \\
\text { ejemplos (types) }\end{array}$ & Porcentaje & $\begin{array}{l}\text { Distribución } \\
\text { temática en el } \\
\text { corpus }\end{array}$ \\
\hline Ciencias de la vida & 29 & $35,36 \%$ & $30,95 \%$ \\
\hline Física & 13 & $15,85 \%$ & $5,95 \%$ \\
\hline Bioquímica & 8 & $9,76 \%$ & $5,95 \%$ \\
\hline Astronomía & 7 & $8,54 \%$ & $10,71 \%$ \\
\hline Geología & 5 & $6,09 \%$ & $16,66 \%$ \\
\hline Economía & 3 & $3,66 \%$ & $2,38 \%$ \\
\hline Sociología & 3 & $3,66 \%$ & $3,57 \%$ \\
\hline Oceanografía & 2 & $2,43 \%$ & $3,57 \%$ \\
\hline Historia & 2 & $2,43 \%$ & $8,66 \%$ \\
\hline Medicina / genética & 3 & $3,66 \%$ & $3,57 \%$ \\
\hline Matemáticas & 1 & $1,22 \%$ & $1,17 \%$ \\
\hline Arte & 1 & $1,22 \%$ & $3,57 \%$ \\
\hline $\begin{array}{l}\text { Otros } \\
\text { cartas lectitoriales, }\end{array}$ & 5 & $6,09 \%$ & - \\
\hline Total & 82 & $100 \%$ & \\
\hline
\end{tabular}

\footnotetext{
${ }^{12}$ Para el análisis cuantitativo consideré las unidades en términos de tipos y no como muestras; por tanto la presencia de anglicismos, en términos de ocurrencias, es mayor.

${ }^{13}$ Bajo "Otros" incluimos ejemplos presentes en editoriales y cartas de lectores que no pueden clasificarse en una disciplina específica.
} 
Esta distribución, naturalmente, debe considerarse en relación con la distribución temática de los artículos, que se corresponde en cierta medida con la presencia de préstamos: las ciencias de la vida (la biología en sus diferentes vertientes y enfoques) es la disciplina a la que se dedica mayor número de artículos (30,95\% de los artículos del corpus), lo cual refleja la importancia de la misma en la investigación actual. La física y la bioquímica muestran un uso importante de préstamos teniendo en consideración el espacio temático que ocupan en la revista. Cabe acotar que muy esporádicamente se emplean préstamos del francés y del italiano en artículos de las áreas de historia, historia de la ciencia y arte ${ }^{14}$.

Como puede verse en la tabla que sigue, las unidades en inglés se acompañan o no de equivalencias en español: un $65,85 \%$ recibe una expresión equivalente mientras que para un $34,15 \%$ de las expresiones no se brinda la equivalencia, si bien en numerosas ocasiones la expresión se explica mediante distinto tipo de procedimientos de tratamiento (definición, reformulación, ejemplo, etc.).

\begin{tabular}{|l|l|l|l|}
\hline & + Equivalencia & - Equivalencia & Total \\
\hline $\begin{array}{l}\text { Número de ejemplos } \\
\text { types) }\end{array}$ & 54 & 28 & 82 \\
\hline Porcentaje & $65,85 \%$ & $34,15 \%$ & $100 \%$ \\
\hline
\end{tabular}

A continuación, presento un caso de un artículo de biología: en el copete o entradilla que se coloca debajo del título, se introduce el concepto con la expresión en español, un marcador metalingüístico (conocidos como) y, a continuación, el préstamo, que constituye la forma que más asiduamente se emplea a lo largo del artículo:

1. Las semillas deterioradas, sin embargo, muestran una notable capacidad de reparación del daño cuando se someten a determinados procesos de humidificación conocidos como priming. $(\mathrm{CH}$ 102: 21$)^{15}$

La primera mención en el cuerpo del texto reitera parcialmente la estrategia usada en la entradilla: la expresión en español y luego su equivalencia en inglés, usando como marca metalingüística solo el signo gráfico del paréntesis. Como puede apreciarse, las remisiones posteriores en el párrafo se realizan con el anglicismo en itálica (priming):

2. Estas semillas muestran una notable respuesta a la humidificación parcial (priming) (...) Este comportamiento sugiere que durante el priming ocurrirían dos procesos: uno inicial, de reacciones de deterioro, seguido por oro de reparación de los daños causados. (...) Sin embargo, si bien la generación de radicales libres podría estar entre los primeros eventos, otros autores no han informado que los tratamientos de priming provoquen una disminución de la GN. (CH 102: 24)

En el caso de que el anglicismo se acompañe de su equivalencia, en un $74 \%$ de los casos se da el orden equivalencia + préstamo (humidificación parcial - priming), mientras que el orden préstamo + equivalencia (Monk Fish - ranas pescadoras-) se da en un 25,55\% de los casos, lo cual indica una actitud de ponderación del español.

A continuación, un ejemplo que documenta el uso del préstamo en el texto sin equivalencia; el fragmento, que proviene de un texto del campo de la física de partículas, expone una taxonomía creada a partir de la unidad quark, un neologismo del tipo ex nihilo. ${ }^{16}$

\footnotetext{
${ }^{14}$ Por ejemplo: "La técnica de Berni apareció así en sus diversas facetas, desde el uso de materiales inusuales hasta la destreza del dibujo directo sobre la capa de preparación del cuadro y sus esporádicas correcciones (técnicamente llamadas pentimenti o arrepentimientos)." $\mathrm{CH}$ vol. 18, nro. 106.

${ }^{15}$ Codificación de los ejemplos: $\mathrm{CH}$, significa Ciencia Hoy, seguido del número de la revista y la página.

${ }^{16}$ Murray Gell-Mann, Premio Nobel de Física en 1969 por su aporte a la teoría de las partículas atómicas, acuñó esta denominación inspirado en la lectura de Finnegans Wake de James Joyce; la forma quark emula el grito de la gaviota.
} 
3. El gran número de partículas que se descubrieron en esos años hacía imperioso dar un nuevo paso en el camino de la simplificación de la teoría. Esto se logró con el concepto de los quarks, partículas que, combinadas de a tres, forman los bariones, mientras que los mesones resultan de la combinación de un quark y un antiquark. Al comienzo se postularon tres tipos (o sabores) de quarks, a los que se denominó up, down y strange respectivamente. (...) A comienzos de 1970 se postuló que debía existir un cuarto quark, el charm, el que efectivamente luego fue observado. (...) en 1977 se descubrió un nuevo quark, que se denominó bottom, y a fines de la década de 1990 se descubrieron el quark top y el neutrino del tau (CH 108: 23).

Los compuestos quark up, quark down, quark strange, quark charm, quark bottom, quark top tienen un origen también deliberado en cuanto al modificador adverbial o adjetival elegido; la literatura de especialidad explica que se eligieron esas denominaciones a los efectos de la practicidad, por su carácter económico y relativamente sencillo de recordar. Esas denominaciones tienen equivalencias en español: respectivamente: quark arriba, quark abajo, quark extraño, quark encanto, quark en fondo y quark cima. Las búsquedas de las equivalencias en el Google en español muestra un uso importante de las mismas, pero muy menor respecto del inglés: por ejemplo, 72700 menciones para quark arriba (vs. 4.870 .000 de quark top), 12100 de quark encanto, (vs. 1.170.000 de quark charm).

Los anglicismos suelen introducirse en muchas ocasiones porque se han establecido bajo la forma de siglas en las distintas disciplinas; como es sabido, el uso de siglas es muy frecuente en el discurso especializado, puesto que permiten realizar las remisiones de manera compactada y así colaboran con la economía de la expresión. En el relevamiento realizado se verifica que un $30 \%$ de los anglicismos ocurre bajo la forma de siglas, que se despliegan en la lengua original acompañadas o no de la traducción al español. A continuación, un fragmento que muestra distintas variaciones en la presentación y despliegue de siglas:

4. Este año, la academia sueca Nobel otorgó el premio de química a los doctores Osamu Shimomura, Martin Chalfie y Roger Tsien, por el descubrimiento, la aplicación y el desarrollo de la proteína verde fluorescente (Green Fluorescent Protein, GFP). A partir de este conocimiento, brillantemente modificó el gen original de la GFP para crear versiones más luminosas, menos fotosensibles y de variados colores. Para fines de los 90, ya estaban disponibles las tres versiones principales derivadas de la GFP original: la CFP (Cyan Fluorescent Protein), eGFP (mejorada o “enhanced”GFP) у YFP (Yellow Fluorescent Protein). (CH 108: 27).

Si se analizan las siglas en inglés surge con claridad que, como en el ejemplo 4, predominan los nombres propios que individualizan objetos, procesos, técnicas, como European Extremely Large Telescope o E-Elt, Barcode of Life Data System (BOLD), o Charged-coupled device o $C C D$; sin embargo también se registran nombres comunes, tanto abstractos como concretos:

5. Técnicamente esto se conoce como ultra alto vacío (sic), o UHV (del inglés ultra high vacuum), y representa el vacío más alto alcanzable actualmente en laboratorios ( $\mathrm{CH}$ 105: 46).

6. Las formaciones de hierro bandeado (Banded Iron Formation = BIF), rocas sedimentarias laminadas en las que alternan capas de sílice con mayor y menor contenido en hierro $(\mathrm{CH} 103$ : 10).

\section{Tratamiento de los préstamos}

Como puede verse en los ejemplos del corpus presentados hasta aquí, los anglicismos, aun cuando no se brinde su equivalente español, son "tratados" (cfr. GÜLICH y KOTSCHI 1995) mediante distintas operaciones de definición y reformulación, de manera de asegurar la comprensión del lector. En el ejemplo que sigue, que proviene de un texto de astronomía, el 
concepto designado por el préstamo (que no se traduce en el artículo) es definido y explicado en detalle:

7. El seeing es uno de los parámetros más importantes para caracterizar un sitio destinado a un instrumento astronómico óptico. Nos da una medida de la calidad y resolución de las imágenes que se pueden obtener en el lugar. Se mide en segundos de arco y es mejor cuanto menor es su valor. Los valores de seeing varían entre los 0,3 segundos de arco (...) y 2 segundos de arco. $(\mathrm{CH}$ 110: 59)

Como puede verse, el concepto se retoma con una repetición idéntica de la forma en la última oración (los valores de seeing). Teniendo en mente la prescripción de las recomendaciones a autores, el uso de este anglicismo llevaría a suponer que no hay un equivalente aceptable en la lengua de la revista. Sin embargo, contra esa expectativa, el glosario que se incluye luego del artículo contiene una entrada visión, que se explica primeramente con la unidad inglesa seeing entre paréntesis, como se consigna a continuación:

8.Visión: (seeing). Es un término utilizado en astronomía para designar al efecto distorsionador de la atmósfera sobre las imágenes de objetos astronómicos. La distorsión de la visión se debe a las turbulencias atmosféricas y a variaciones de densidad del aire que deforman el camino recorrido por los rayos de luz llegados de objetos exteriores a la atmósfera. (CH 110: 64).

En ocasiones, como es el caso del artículo precedente, los autores incluyen glosarios al final del artículo - y, en algunos casos, cuando se trata de números completos dedicados a un solo tema, al final del volumen -. Ocasionalmente, las entradas son anglicismos, unidades léxicas completas o siglas, aun cuando exista y se haya brindado en el texto la equivalencia en español, por ejemplo:

9. Molecular farming: Término dado a la producción por medio de plantas transgénicas de una gran diversidad de moléculas recombinantes, como proteínas de interés farmacéutico, vacunas, anticuerpos, enzimas o bioplásticos, para usos medicinal, científico o industrial. (CH 107:30)

En el artículo, el término había sido introducido primeramente en español como cultivo molecular, y luego "tratado" en inglés, reconociéndose con un marcador metalingüístico ${ }^{17}$ (conocido como...) su mayor difusión en esa lengua:

10. Esto dio origen al desarrollo de una nueva tecnología denominada cultivo molecular (conocido como molecular farming por su nombre en inglés) ( $\mathrm{CH}$ 107: 23)

En estos casos, los glosarios adquieren cierto grado de "hibridez", puesto que introducen y explican la terminología científica en español pero también incluyen entradas en inglés, que en el texto principal ya se han introducido con su forma castellana. A continuación, otros casos de anglicismos como entradas de glosarios, establecidos en forma de siglas:

11.GFP (Green Fluorescent Protein): Es un gen que codifica para una proteína que emite fluorescencia al ser excitada con una luz determinada. Se la utiliza como proteína reportera, ya que si esta se expresa es porque el tejido vegetal fue efectivamente transformado (CH 107:30)

12. PCR (del inglés Polymerase Chain Reaction, o reacción en cadena de la polimerasa): Técnica de biología molecular empleada para la amplificación de porciones conocidas de ADN.

\footnotetext{
${ }^{17}$ Señalo las expresiones metalingüísticas con subrayado.
} 
Esta actitud de manifiesta indiferencia a la lengua de las entradas muestra la fuerza del inglés en determinadas disciplinas y el uso extendido del préstamo aun cuando haya disponibilidad y se use el equivalente en español. ${ }^{18}$

\section{Calificación metadiscursiva}

Una cuestión interesante por dilucidar es el grado de integración del inglés en los textos escritos por los especialistas o, en otros términos, si se hace evidente o no la introducción del otro código mediante marcadores metalingüísticos de distinto tipo, mediante los cuales los autores de los textos comentan y/o valoran las expresiones que emplean (GÜLICH y KOTSCHI 1995; CIAPUSCIO, 2007). La pregunta por lo que podría llamarse el grado de heterogeneidad glósica puede ser un dato de interés para determinar actitudes lingüísticas y para reflexionar sobre las funciones que cumplen los préstamos en los textos.

De manera consistente, en todos los casos, los anglicismos son marcados con itálicas al igual que las equivalencias, cuando se proveen. Ahora bien, puede observarse en el corpus un repertorio diferenciado de recursos que introducen o marcan el anglicismo, de acuerdo con el grado de evidencia o de opacidad que se quiera dar a la expresión. Ese repertorio puede ordenarse en una escala gradual con dos polos, que se caracterizan por $+/$ - opacidad.

\section{+ opacidad / + integración del préstamo en los textos}

\section{Itálicas}

Marcadores gráficos (paréntesis, guiones)

Marcadores reformulativos (o, esto es)

Verbos metalingüísticos (llamar, denominar, referir, ser conocido, traducido)

Marcadores léxicos de código lingüístico (en inglés, en la literatura en inglés, etc.)

\section{- opacidad / - integración del préstamo en los textos}

A continuación mediante algunos ejemplos del corpus ilustro lo antedicho:

13. Los desafíos fundamentales en la terapia contra el cáncer son el targeting y el delivery localizado. El targeting es la capacidad de la droga de llegar al sitio o blanco específico y el delivery es la capacidad de entrega o liberación de la droga en dicho blanco. Idealmente, se debería poseer una droga inteligente que atravesara las numerosas barreras biológicas existentes en el organismo, llegara al target (blanco) constituido por las células tumorales, marcara claramente sus posiciones para una posible cirugía o las destruyera con tal precisión que dejara las células sanas adyacentes intactas (CH 115: 43).

En el ejemplo 13 se incluyen los préstamos targeting y delivery, sin proveer las equivalencias en español ${ }^{19}$, y target con su equivalencia (blanco), aunque, a lo largo del artículo las remisiones se realizan con el término en inglés. Estos anglicismos proceden y se usan profusamente en otros dominios de especialidad (el marketing y el comercio, y también, en el caso de targeting, en criminología ${ }^{20}$, y delivery es de uso asiduo en la vida cotidiana (reparto de

\footnotetext{
${ }^{18}$ Además de desconocimiento de criterios lexicográficos.

${ }^{19}$ Existe manipulación como equivalencia de targeting, pero es claro que el anglicismo domina en la literatura de especialidad.

${ }^{20}$ Con el sentido de "criminalización", es decir, la construcción social del delincuente o criminal.
} 
comidas, bebidas, etc., a domicilio), lo cual les otorga cierta transparencia que podría explicar la ausencia de traducción: los préstamos se incluyen en el discurso en español sin otra marca que las itálicas, de manera que se produce una continuidad en el discurso que integra el anglicismo casi como si se tratara de una unidad del español y genera así un efecto de homogeneidad glósica.

En numerosos casos, el anglicismo se introduce entre paréntesis, a continuación de la expresión en español:

14. La evolución por unión (evolution by merger) es reconocida desde hace algún tiempo, como consecuencia del trabajo de Lynn Margulis sobre el origen bacteriano de las organelas (mitocondrias, cloroplastos). CH 113: 9

La yuxtaposición del anglicismo al término en español puede obedecer a distintos motivos que entran en un campo conjetural. Sin embargo, es claro que en general se trata de denominaciones creadas originalmente en inglés (como en 14, en que se cita a la investigadora estadounidense); de allí que, muy probablemente, la inclusión del anglicismo tenga por propósito aportar a la comprensibilidad de la equivalencia en español, y también, a su difusión.

En el ejemplo que sigue, del campo de la economía, se puede observar un profuso trabajo metalingüístico para explicar una expresión en inglés - free rider -, que sobre la base de una metáfora $^{21}$ designa un concepto especializado:

15.Estos resultados han sido muy importantes en la literatura sobre bienes públicos, pues encuentran una solución al problema de quien recibe un beneficio sin pagarlo (o free rider, expresión que en el argot local podría traducirse por "colado", aunque también se puede hablar de externalidades negativas, que se refieren a quienes no tienen en cuenta costos impuestos sobre otros participantes al tomar sus decisiones económicas), y permiten establecer una forma de financiar el bien que no sea excesiva ni insuficiente. (CH 102:49).

A continuación de una expresión que describe el concepto (quien recibe un beneficio sin pagarlo) se introduce el anglicismo mediante el conector reformulativo $o$; luego, mediante un enunciado que contiene distintas expresiones metalingüísticas, los autores ofrecen alternativas denominativas: en primer lugar, colado, una opción de la variedad argentina popular, descripta como "argot local" y, seguidamente, una segunda opción, externalidades negativas, término económico que clarifica el sentido del anglicismo.

Los préstamos, en otros casos, se señalan con marcadores léxicos que incluyen la mención de la lengua inglesa, haciendo así ostensible la inclusión de otro código. Las expresiones léxicas que se identifican en el corpus son: en inglés, conocido en su nombre en inglés, en la literatura en inglés, por su sigla en inglés, del inglés, del mundo anglosajón, etc. El ejemplo 16 ilustra esta modalidad: es interesante que en este caso se trata de una unidad fraseológica del inglés, para la que se ofrece a continuación una traducción en español:

16. La representación nutre la posibilidad de librarse de los moldes establecidos, tomar distancia de la propia configuración mental y abordar un problema desde una nueva perspectiva. En la literatura en inglés ello se expresa como to think out of the box (pensar fuera de la caja). (CH 111: 33)

La expresión, inexistente en español, condensa de manera prístina la conclusión del artículo. En 17, en que los anglicismos corresponden a categorías adverbiales - una rareza en el corpus se afirma elípticamente el carácter de lengua franca del inglés para la comunicación especializada:

\footnotetext{
${ }^{21}$ Literalmente "jinete solitario".
} 
17. El próximo paso, proporcionar acceso a la banda ancha en forma ubicua y sin discontinuidad (ubiqitously and seamlessly, en la jerga de la literatura internacional) puede ocurrir dificultosa y turbulentamente (CH 119:6)

Los siguientes ejemplos presentan un interés especial: además de contener un préstamo señalado con un marcador metalingüístico de código, muestran cómo los autores de Ciencia Hoy manifiestan un claro interés por acrecentar el acervo léxico de sus lectores, ofreciendo alternativas denominativas relacionadas con distintas dimensiones de variación:

18. Dichos instrumentos se conocen técnicamente como registradores de múltiples sensores, y más sencillamente como acelerómetros (en inglés daily diaries) (CH 114:22).

19. En la Argentina suele llamárselo torito, carachai o jején; en inglés su nombre coloquial es sand fly, esto es, mosca de la arena. (CH 114:33)

En el ejemplo 18, además del marcador de código (en inglés), se pueden observar marcadores de grado de especialidad (técnicamente, más sencillamente), en el ejemplo 19 podemos identificar un marcador diatópico (En la Argentina) y un marcador diastrático (nombre coloquial). Estos y otros ejemplos similares del corpus muestran una tendencia a la variación denominativa, que favorece la comprensibilidad, una de las normas internas distintivas de la divulgación científica.

En resumen: en las secciones precedentes se han presentado variados ejemplos que ilustran los modos de ocurrencia de los préstamos, los procedimientos de tratamiento y de calificación metadiscursiva que reciben, haciéndose hincapié en el grado de integración en los textos escritos en español. En la sección que sigue, nos ocupamos de las funciones que cumplen los préstamos en los textos.

\section{Funciones textuales y pragmáticas de los préstamos}

En esta sección realizo unas consideraciones cualitativas que surgen del análisis del corpus. He realizado una primera categorización entre los préstamos que se emplean solos y los que se emplean con equivalentes. En el primer caso puede tratarse de sintagmas nominales de distinto grado de complejidad, incluyendo las siglas y su despliegue en inglés (ver ejemplos 4, 5 y 6). Los préstamos cumplen una función principal, la de introducir y nombrar conceptos (sean individuos o eventos), que son centrales para el tema del texto. La preferencia por el préstamo, en estos casos, parece orientarse en el deseo de precisión, puesto que en muchos casos el concepto es conocido en la disciplina por el término en inglés. El empleo asiduo de siglas, como es sabido, favorece las remisiones a lo largo del texto y colabora con la economía y simplicidad de la expresión, atributos esenciales del discurso científico. Por lo tanto, este uso del préstamo en función principal - la coherencia temática y la cohesión gramatical - se orienta en las máximas de Grice "Be relevant", "Be brief" y "Be true". En esta función principal de servir a la referencia textual los préstamos tienden a incorporarse con un alto grado de opacidad, es decir, despojados de marcadores metalingüísticos de orden léxico (por ejemplo, los casos 2, 3, 7 y 13, entre otros).

El segundo grupo de préstamos que he distinguido es aquel cuyo empleo es paralelo a las unidades en español: las razones en que se basan los autores para traducir al inglés las expresiones son en buena parte campo de conjetura del analista, si bien en algunos casos pueden brindarse interpretaciones plausibles. Díaz Rojo afirma con razón que la introducción de préstamos en la lengua general - cuando existen denominaciones disponibles en la lengua vernácula - está motivada en factores como la moda, el deseo de distinción social, el afán de notoriedad y, muy frecuentemente, el eufemismo (su ejemplo es el caso del castizo retrete que 
ha sido sustituido por el foráneo váter, y este a su vez por baño o aseo, y también en nuestra variedad rioplatense, agregamos, toilette). En el caso de los textos de Ciencia Hoy puede aducirse que operan otros factores, vinculados con razones de orden ideológico y de política editorial. En primer lugar, dado que la revista - como lo veíamos al comienzo - tiene pretensiones de convertirse en un foro latinoamericano de la ciencia, suele brindar variaciones denominativas de las expresiones, que corresponden a las distintas normas regionales, como lo muestra el siguiente ejemplo proveniente de un glosario:

20. Arribazón. Es un fenómeno natural que consiste en el depósito en la costa de algas que fueron arrancadas por los movimientos del agua. También se lo conoce en otros países como algazo. ${ }^{22}$

Numerosos ejemplos en que se introducen clases de objetos (nombres de especies) la inclusión del inglés parecería explicarse a partir de una intención de ampliar el campo de destinatarios, facilitando la comprensión y el acceso al concepto a través de las distintas denominaciones ofrecidas:

21. Ante ese hecho, Haeckel ideó una forma teórica que cumpliera con la función de eslabón. La denominó Pithecanthropus (del griego pithecus, mono, y anthropos, hombre). Así, hacia finales del siglo XIX, tomó carta de ciudadanía científica y se difundió entre el público culto la noción de eslabón perdido (en inglés, missing link o vínculo faltante). (CH 115: 56). Biología

En estos casos, la función suele ser subsidiaria, es decir, los préstamos no forman parte de un referente textual principal, y no se limitan a categorías nominales, sino que incluyen expresiones adverbiales y oracionales (por ejemplo, los casos de 16 y 17). La máxima que parece guiar el empleo de préstamos y las alternativas denominativas en las distintas variedades del español (ver también ejemplos 18, 19 y 21) es "Be clear", "Avoid ambiguity". Como se ha visto, en estos casos los préstamos se "muestran" mediante marcadores metalingüísticos de orden léxico que señalan las diferencias de códigos produciendo lo que se ha llamado la heterogeneidad glósica.

En otros casos, se brindan las equivalencias de nombres propios correspondientes a objetos o conceptos individuales relevantes para el conocimiento general; podría conjeturarse que el propósito es ampliar el horizonte cultural y el conocimiento enciclopédico del potencial lector; en suma, la norma de referencia se referiría a la dimensión de la imagen (cfr. ANTOS 1982, p.74), que se refiere a la construcción del perfil del autor y del lector:

22. El gran acelerador de partículas construido en Ginebra, llamado Gran Colisionador de Hadrones (Large Hadron Collider) (CH 110: 10).

23. La institución europea investiga dónde instalar uno de gran tamaño, dotado de un espejo de 42 m de diámetro, denominado Telescopio Europeo Extremadamente Grande (en inglés European Extremely Large Telescope o E-Elt). (CH 110: 58).

24. Como lo explica el texto, desde 1894, la base crecientemente adoptada por los países para sus horas civiles fue la hora establecida por el Real Observatorio de Greenwich, correspondiente al meridiano de esa localidad y denominada tiempo medio de Greenwich (Greenwich Mean Time). (CH 112:38).

\section{CONCLUSIONES}

\footnotetext{
${ }^{22}$ Ciencia Hoy, vol. 18, nro. 107, febrero-marzo 2007, 39.
} 
Intentaré ahora retomar las preguntas que planteé al comienzo. ¿Cuándo y por qué razones se incluyen préstamos del inglés en una revista de ciencia que recomienda prescindir de ellos? En primer lugar, ha quedado manifiesto que los préstamos tienen una distribución claramente desigual según la disciplina: los ejemplos recogidos en la muestra ejemplar provienen mayormente de la biología, la biología molecular, la química, la física y la astronomía. En términos generales, la ocurrencia de anglicismos en los artículos de ciencias sociales y humanidades es casi nula. Los préstamos se incluyen entonces en las disciplinas en las que los objetos de investigación son más independientes de la cultura, disciplinas en las cuales prevalece el inglés como lengua de investigación; la divulgación "alta" de estas disciplinas aun cuando la norma explícita de la publicación lo desaconseje - preserva parcialmente los usos y costumbres del ámbito de la investigación, en el que los especialistas tienden a emplear con asiduidad el inglés y éste es la lengua franca de las publicaciones originales. Por otra parte, puede presumirse que el carácter conocido del préstamo - por su uso en otros dominios especializados o no (target, delivery, chip) - habilita la colisión con la norma de la revista. Sin embargo, en otros casos se ha visto cómo también la revista incurre en contradicciones entre su representación normativa explícita y el uso real (seeing/visión).

El análisis ha mostrado que el empleo de préstamos no responde a falta de equivalencias o de recursos morfológicos del español para expresar los conceptos acuñados inicialmente en inglés, puesto que, consistentemente con su normativa, la revista define y explica los anglicismos: antes bien, se observa que el motivo de su ocurrencia es el alto grado de imposición del anglicismo en determinadas disciplinas. Incluso, se puede conjeturar que en ocasiones el anglicismo se introduce para desambiguar la expresión en español.

En segundo lugar, como lo han mostrado los ejemplos, los préstamos se incluyen en contextos de procedimientos de composición textual, de tipo reformulativo o calificativo (para explicar o comentar y evaluar expresiones), es decir, en el contexto de zonas textuales dedicadas al trabajo léxico para asegurar la comprensión. Los glosarios que suelen acompañar algunos artículos o números especiales constituyen un aporte de calidad que debería ser un insumo importantísimo para la lexicología especializada del español. Algunos de ellos contienen entradas en inglés, y de este modo confirman la fuerza de penetración de esa lengua en algunas disciplinas. Los anglicismos son integrados en los textos con distinto grado de opacidad, según ha mostrado el análisis de los marcadores metalingüísticos. El modo de integrar los préstamos parece estar en relación con la función textual y/o pragmática que estos cumplen: en función principal, la de introducir y mantener la referencia, se observa mayor grado de integración y opacidad. En cambio, en función subsidiaria, cuando se trata de brindar alternativas denominativas para dar mayor comprensibilidad (lo que Diéguez, 2005, llama "sub-función variación"), la mostración del anglicismo es mayor.

Las normas de referencia que operan detrás de la decisión de incluir préstamos, con o sin equivalencias, son especialmente pertinentes las dimensiones de relevancia ("Be relevant" y "Be brief") y la dimensión de comprensibilidad, que define la divulgación de ciencia ("Avoid obscurity of expression" y "Avoid ambiguity"); también tiene su influencia la dimensión de la imagen de los interlocutores, cuando el propósito es difundir nombres propios de individuos y nociones relevantes del mundo de la ciencia.

Finalmente, la norma editorial de Ciencia Hoy "No emplear palabras extranjeras si hubiese razonables equivalentes castellanos", como tal, forma parte de la preceptiva ideal de la revista $\mathrm{y}$, evidentemente, colisiona con algunos de los usos observados, en que las formas y estructuras del español están disponibles. Sin embargo, esa colisión con la norma explícita responde a la realidad de que el inglés, en algunas disciplinas, es la lengua franca, y por lo tanto, para comunicar los avances y hallazgos en esos campos, es preciso llevar a cabo un elaborado trabajo léxico en las lenguas vernáculas. Puede concluirse que, desde su fundación en 1988, Ciencia Hoy está ampliando la cultura lingüística de sus lectores y aportando a la conformación de la tradición escrita del español científico: su labor de instaurar y difundir la terminología de las distintas disciplinas, que no excluye, cuando es pertinente, la variación regional, propia de una 
lengua pluricéntrica, constituye un fundamento de calidad para el estudio sistemático de la variedad científica del español contemporáneo.

\section{BIBLIOGRAFIA}

ALZUGARAY, Juan José. En defensa de la lengua española. Madrid: Ediciones Encuentro, 2004.

ANTOS, Gerd. Grundlagen einer Theorie des Formulierens. Tübingen: Niemeyer, 1982.

ANTOS, Gerd. Laien-Linguistik. Tübingen: Max Niemeyer Verlag, 1996.

CASTILLO FADIC, Natalia. El préstamo léxico y su adaptación: un problema lingüístico y cultural. Onomázein 7, p. 469-496, 2002.

CIAPUSCIO, Guiomar. Normas y variedades lingüísticas en los textos de divulgación científica: el caso de revistas de Argentina y México. In: LEBSANFT, Franz, Wiltrud MIHATSCH \& Claudia POLZIN-HAUMANN. El español, lengua pluricéntrica. Madrid: Frankfurt: Editorial Vervuert / Iberoamericana. Serie Lengua y sociedad en el mundo hispánico, (en prensa).

CIAPUSCIO, Guiomar. Acciones de calificación en conferencias de divulgación científica. Revista Internacional de Lingüística Iberoamericana (RILI), Frankfurt: Vervuert Vlg, volumen V, Nro. 1 (9), p. 59-77, 2007.

DÍAZ ROJO, José. El latín y el inglés como lenguas científicas. Nota comparativa, Boletín de la Sociedad Andaluza de Bibliotecarios 33, p. 57-59, 1993.

DÍAZ ROJO, José. ¿Qué hacer con los extranjerismos lingüísticos?. Medicina Clínica, vol. 104, número 7, p. 44-45, 1995.

DIÉGUEZ María Isabel. Análisis contrastivo del anglicismo léxico en el discurso económico semiespecializado y de divulgación científica del español de Chile. Onomázein 12, 129-156. 2005.

GÜLICH, Elisabeth y Thomas KOTSCHI. Discourse Production in Oral Communications. In: QUASTHOFF, Ulla (ed.) Aspects of Oral Communication, Berlin: De Gruyter, 1995. p. 30-66.

HAVRANEK, Bohuslav. Zum Problem der Norm in der heutigen Sprachwissenschaft und Sprachkultur. In: VACHEK, Josef (ed.), A Prague School reader in linguistics, 1936. p. 413420.

KRETZENBACHER, Heinz. Looking backward - Looking forward - Still Looking Good? On style in Academic Communication. In: MAYER, Felix (ed.) Language for Special Purposes: Perspectives for the New Milenium, Tübingen: Narr, 2001. p. 443-459.

LARA, Luis Fernando. El concepto de norma en lingüística. México: El Colegio de México, 1976.

LARA, Luis Fernando. Por una reconstrucción de la idea de la lengua española. In: DEL VALLE, José (ed.). La lengua, ¿patria común?, Madrid: Iberoamericana/ Vervuert, 2007.

NAVARRO, Francisco. (ed.) Traducción y lenguaje en medicina. Barcelona: Fundación Antonio Esteve, 1997.

PRATT, Charles. El anglicismo en el español peninsular contemporáneo. Madrid: Gredos, 1980.

WEINRICH, Harald. Formen der Wissenschaftssprache. In: WEINRICH, Harald; KRETZENBACHER, Heinz (eds.). Akademie der Wissenschaften zu Berlin, Jahrbuch 1988Berlin/New York: Walter de Gruyter, 1989. p. 119-158. 